\title{
A Cumulative Degree-Day-Based Model to Calculate the Duration of the Incubation Period of Guignardia bidwellii
}

Daniel Molitor, Section of Phytomedicine, Geisenheim Research Center, 65366 Geisenheim, Germany, and Department Environment and Agro-Biotechnologies, Centre de Recherche Public - Gabriel Lippmann, 4422 Belvaux, Luxembourg; Cathleen Fruehauf, Centre of Agrometeorological Research, Deutscher Wetterdienst (German Meteorological Service), 38116 Braunschweig, Germany; and Ottmar Baus and Beate Berkelmann-Loehnertz, Section of Phytomedicine, Geisenheim Research Center, Germany

\begin{abstract}
Molitor, D., Fruehauf, C., Baus, O., and Berkelmann-Loehnertz, B. 2012. A cumulative degree-day-based model to calculate the duration of the incubation period of Guignardia bidwellii. Plant Dis. 96:1054-1059.

The duration of the incubation period of Guignardia bidwellii on leaves and clusters of Vitis vinifera strongly correlates to temperature. To describe this relationship mathematically, a new, cumulative degreeday-based model was developed. According to this model, first symptoms on leaves appear after reaching a threshold of 175 cumulative degree-days (calculated as the sum of average daily temperatures between 6 and $24^{\circ} \mathrm{C}$ starting on the day after the infection). On clusters, the duration of the incubation period is additionally affected by their respective developmental stages. For 'Riesling', the duration of the incubation period on clusters corresponds to the duration on

leaves until reaching the phenological stage "berries beginning to touch" but extends continuously with ongoing phenological development. Therefore, a correction factor recognizing cluster phenology was derived to calculate the cumulative degree-day thresholds for the occurrence of first symptoms on clusters after reaching "majority of berries touching". Hence, this present model allows the estimation of fungal development and forecasts the appearance of new symptoms on leaves as well as on clusters, enabling growers to more precisely schedule curative as well as protective fungicide applications against grape black rot.
\end{abstract}

Black rot, caused by Guignardia bidwellii (Ellis) Viala \& Ravaz (anamorph: Phyllosticta ampelicida (Engelm.) Aa) is a grape disease native to North America (5). In Europe, it was first described at the end of the 19th century (3) and is most prevalent in regions with humid conditions in spring and early summer (6). In Germany, the presence of black rot was documented in the 1930s $(9,14)$. However, no major epidemics occurred until 2002 (3). Since that year, black rot has become well established in the northern wine-growing areas of the country and represents, to date, one of the major fungal grape diseases in some regions (3). Black rot poses a threat to both yield and wine quality, and crop losses can reach up to $80 \%$ (6).

In Germany, black rot management strategies are currently focused mainly on routine applications of fungicides containing strobilurins, triazoles, or dithiocarbamates, which have proven their potential to control the disease in several studies $(2-4,12,18)$. Strobilurins and triazoles, especially, are of excellent curative activity against black rot $(4,12,18)$. For example, full control of developing infections was achieved on leaves and clusters with an application of the strobilurin-type active ingredient pyraclostrobin, even if more than $85 \%$ of incubation period had already passed (12). However, in order to optimally exploit this curative potential, the duration of the incubation period has to be known.

Spotts (20) found that successful black rot infections are possible only if specific temperature-dependent wetness durations are achieved. This means that the occurrence of black rot infections can be detected in the vineyards by using recorded weather data (temperature and wetness period duration). These infection events represent the starting points of incubation periods. The meteorological requirements for a successful infection process of $G$. bidwellii are well understood $(7,10,18)$. However, an

Corresponding author: D. Molitor, E-mail: dmolitor@lippmann.lu

Accepted for publication 17 February 2012.

http://dx.doi.org/10.1094/PDIS-11-11-1005-RE

(C) 2012 The American Phytopathological Society algorithm describing the duration of the incubation period is missing.

G. bidwellii is able to infect all green, expanding tissues (7) of grapevine; however, infections on leaves and young berries are of major importance for the epidemic. Kuo and Hoch (7) documented that leaves inoculated with conidia under greenhouse conditions typically express symptoms 10 to 14 days after infection. Spotts (21) further described that the duration of the incubation period on leaves is influenced by temperature conditions. However, Spotts (21) monitored only seven temperature steps, which were predominantly higher than the temperatures normally prevalent in the German wine-growing regions. Furthermore, his examinations were conducted exclusively with Vitis labrusca or hybrid grape. Hence, the impact of the temperature on the duration of the incubation period on leaves has never been investigated and described for $V$. vinifera cultivars, which are the predominant grape varieties grown in the European winegrowing regions.

On clusters, examinations of the duration of the incubation period were conducted by Northover (16) and Hoffman et al. (5). The latter found that the duration of the incubation period is affected not only by the temperature conditions but also by the phenological growth stage. However, an algorithm to model the impact of this factor has not been developed.

Hence, this study aimed to (i) collect multi-annual experimental data as a basis for modeling the onset of symptoms on $V$. vinifera leaves and clusters; (ii) develop an algorithm, based on these data, to calculate the impact of temperature conditions on the duration of the incubation period on leaves; and (iii) gather a correction factor to calculate the incubation period duration on clusters, based on an algorithm to describe the impact of the current phenological stage. Knowledge regarding the duration of the incubation period could be used as a decision support tool for more targeted timing of fungicides with pre- and post-infection activity.

\section{Materials and Methods}

Recording incubation period on leaves. During 2007 and 2008, each week, four potted vines ('Mueller-Thurgau') were inoculated with conidia of G. bidwellii from 2 April until 24 September and from 31 March until 22 September, respectively. 
Hence, each experimental year had 26 inoculation dates. Before inoculation, potted vines were cultivated for 2 to 3 months in a greenhouse at temperature conditions of around $20^{\circ} \mathrm{C}$. Inoculation took place when six to nine leaves per plant were unfolded $(\mathrm{BBCH}$ 16 to 19) (8). Greenhouse-cultivated potted vines were used to keep the developmental stage of leaves constant through the season.

The G. bidwellii isolate used (Mo05, culture collection Geisenheim) was isolated from an infected berry in a commercial vineyard in the Moselle Valley in 2004. Annually, leaves of potted vines were inoculated with a conidial suspension and, after the appearance of the symptoms, the fungus was reisolated from conidia. This subsequent isolate was used for examinations in the following year. Cultivation of the fungus took place on oatmeal agar for 2 to 3 weeks under cycles of $12 \mathrm{~h}$ of light and $12 \mathrm{~h}$ of darkness at $20^{\circ} \mathrm{C}$. Thereafter, conidia were harvested by floating the plates with water. The density of the conidial suspension was adjusted to $2.5 \times 10^{4}$ conidia/ml. This inoculum dose was demonstrated in preliminary tests (data not shown) to ensure reliable infection and disease development. Inoculation was carried out on the five youngest unfolded leaves of each plant at $20^{\circ} \mathrm{C}$ using a hand sprayer. Approximately $25 \mathrm{ml}$ of conidia suspension were used per plant. After inoculation, potted vines were put in plastic bags impervious to light for $20 \mathrm{~h}$ to maintain the required leaf wetness. Inoculation, as well as the following wetness period, took place indoors under constant temperature conditions $\left(20^{\circ} \mathrm{C}\right)$. Thereafter, potted vines were placed outdoors.

Each morning, plants were checked visually for initial leaf lesions and pycnidia. The end of the incubation period was defined as the day when the first necrotic, brownish lesions were observed on any leaf of the four plants. The incubation period duration was calculated by summing the days between the day after inoculation and the day of the appearance of initial symptoms (day of appearance included).

Cumulative degree-day model to determine the incubation period on leaves. In order to estimate the duration of the incubation period of $G$. bidwellii on grape leaves, a model based on cumulative degree-days (CDDs) bounded by upper and lower thresholds was developed. For the calculation of the $\operatorname{CDD}_{\text {INC }(a ; b)}$, the following formula was used:

$\mathrm{CDD}_{\mathrm{INC}(\mathrm{a} ; \mathrm{b})}=\sum_{i=m+1}^{n} t(i)$

where $t(i)=0^{\circ} \mathrm{C}$, if $t_{\mathrm{av} ; \mathrm{i}}<\mathrm{a} ; t(i)=t_{\mathrm{av} ; \mathrm{i}}-\mathrm{a}^{\circ} \mathrm{C}$, if $\mathrm{a}<t_{\mathrm{av} ; \mathrm{i}}<\mathrm{b}$; and $t(i)$ $=\mathrm{b}-\mathrm{a}^{\circ} \mathrm{C}$, if $\mathrm{b}<t_{\mathrm{av} ; \mathrm{i}} \cdot \mathrm{CDD}_{\mathrm{INC}(\mathrm{a} ; \mathrm{b})}$ is the CDD (average daily temperatures $\left[{ }^{\circ} \mathrm{C}\right.$ ] between a and b) until first symptoms occur, a is the lower temperature threshold $\left({ }^{\circ} \mathrm{C}\right), \mathrm{b}$ is the upper temperature threshold $\left({ }^{\circ} \mathrm{C}\right), t_{\mathrm{av} ; \mathrm{i}}$ the average daily temperature $\left({ }^{\circ} \mathrm{C}\right)$ on day $i, t(i)$ the adjusted temperature $\left({ }^{\circ} \mathrm{C}\right)$ for the day $i, m$ the day of inoculation, and $n$ the day of occurrence of first symptoms.

Recording incubation period on clusters. Experiments were conducted during 3 years on clusters of $V$. vinifera 'Riesling' (grafted on 5C rootstock) in a vineyard planted in 1998 in Geisenheim, Germany $\left(49.98^{\circ} \mathrm{N}, 7.95^{\circ} \mathrm{E}\right)$. The natural black rot pressure in this vineyard was low. Preliminary tests on leaves indicated no differences in the duration of the incubation period between the two $V$. vinifera varieties Riesling and Mueller-Thurgau.

In the years 2006 to 2008 , each week, 10 clusters on each of four replicate plants were inoculated from approximately 1 week before to 8 weeks after the developmental stage BBCH 68 (" $80 \%$ of flowerhoods fallen") (8), using a randomized complete block design. BBCH 68 occurred in 2006 on 20 June, in 2007 on 29 May, and in 2008 on 8 June. Conidia were produced as described for the leaf experiment, and the density of the suspension was adjusted to $1 \times 10^{4}$ conidia/ml. This density was proven to be sufficient to guarantee an adequate infestation level on clusters (10). Inoculations were conducted with a hand sprayer by applying around $5 \mathrm{ml}$ of conidia suspension per cluster. After the inoculation, grape berries were bagged for $16 \mathrm{~h}$ to provide the required wetness period. Inoculation was always carried out in the early evening to avoid heating and sunburn due to intense sun radiation. The clusters were inspected visually at least three times a week to detect developing black rot lesions. The end of the incubation period was determined when the first typical brownish lesions on the berries were observed on any of the inoculated clusters. The incubation period duration was calculated by cumulating the days between the day after inoculation and the day of the appearance of initial symptoms. To avoid potential confounding effects, Plasmopara viticola and Erysiphe necator were controlled in the time span between $\mathrm{BBCH} 15$ and 81 (8) with fungicides containing exclusively active ingredients without black rot activity (i.e., dithianon, folpet, and metrafenone).

To describe the developmental stage of grape berries at the moment of inoculation, a second CDD model was developed. In this model, the average daily temperatures starting the day after reaching $\mathrm{BBCH} 68$ until the day of inoculation were summed $\left(\mathrm{CDD}_{>10}\right)$. The temperature value of the lower threshold was fixed at $10^{\circ} \mathrm{C}$ according to the leaf area growth model developed by Schultz (17). Table 1 shows average $\mathrm{CDDs}\left(\mathrm{CDD}_{>10}\right)$ required to reach the different developmental stages (data recorded in Eltville, Rheingau, Germany in Riesling in the years 1995 to 2007; 11).

To adjust the CDD threshold determined for leaves to the conditions prevailing on clusters a correction factor for the phenological development is necessary:

$\mathrm{CDDT}_{\text {CLUSTER(6;24) }}=\mathrm{CDDT}_{\operatorname{LEAF}(6 ; 24)} \times \mathrm{c}$, where $\mathrm{CDDT}_{\text {CLUSTER(6;24) }}$ is the CDD threshold on clusters, $\mathrm{CDDT}_{\mathrm{LEAF}(6 ; 24)}$ is the CDD threshold on leaves, and $\mathrm{c}$ the correction factor.

Meteorological data and data processing. Temperature was recorded by a weather station of the Deutscher Wetterdienst (German Meteorological Service), located at a distance of approximately $300 \mathrm{~m}$ from both experimental areas. Average daily temperatures were calculated by averaging temperatures measured on an hourly basis. Data were processed with Microsoft Excel 2000 and statistically tested using PASW Statistics 18 .

\section{Results}

Incubation period on leaves. The duration of the incubation period on potted vines in 2007 and 2008 was 12 to 43 days. In both years, a strong correlation between the average temperature during the incubation period and the duration of the incubation period was visible (Fig. 1).

Initial symptoms appeared on all plants on virtually the same day, and no differences were found in the duration of the incubation period on leaves of different ages.

Based on the results of the year 2007, CDD models with different lower and upper thresholds were tested (Table 2). The coeffi-

Table 1. Average cumulative degree-days $\left(\mathrm{CDD}_{>10}\right)$ between $\mathrm{BBCH} 68$ and $\mathrm{BBCH} 71,73,75,77,79$, and 81 on grape in Eltville, Rheingau, Germany over the period 1995 to 2007

\begin{tabular}{lccrrrrr}
\hline & \multicolumn{7}{c}{${\text { Phenological growth stage }(\mathbf{B B C H})^{\mathbf{a}}}$} \\
\cline { 2 - 7 } & $\mathbf{7 1}$ & $\mathbf{7 3}$ & $\mathbf{7 5}$ & $\mathbf{7 7}$ & $\mathbf{7 9}$ & $\mathbf{8 1}$ \\
\hline $\mathrm{CDD}_{>10}$ & 54.9 & 88.3 & 157.8 & 196.8 & 255.8 & 613.1 \\
Standard error & 4.0 & 4.1 & 5.3 & 6.5 & 12.0 & 15.3 \\
\hline
\end{tabular}

${ }^{a} \mathrm{BBCH}$ 71: fruit set, young fruit begin to swell, remains of flowers lost; $\mathrm{BBCH} 73$ : berries groat sized, bunches begin to hang; $\mathrm{BBBH}$ 75: berries pea sized, bunches hang; $\mathrm{BBCH}$ 77: berries beginning to touch; $\mathrm{BBCH} 79$ : majority of berries touching; and $\mathrm{BBCH} 81$ : beginning of ripening, berries begin to develop variety-specific color (8). 
cient of variation (standard deviation/average CDD) was used to determine the model, which provided the best forecast of the duration of the incubation period.

To predict the time interval between the day after the inoculation and the day of initial symptom occurrence, a model using CDDs with a lower threshold of $6^{\circ} \mathrm{C}$ and an upper threshold of $24^{\circ} \mathrm{C}$ $\left(\mathrm{CDD}_{\mathrm{INC}}\right)$ was proven to be best adapted to the data of the year 2007, due to the lowest coefficient of variation (Table 2).

In 2007, first symptoms became visible after reaching 165.6 to 198.2 CDDs $\left(\mathrm{CDD}_{\text {INC }}\right)$. The average and the median $\mathrm{CDD}_{\text {INC }}$ value for the occurrence of first symptoms were 177.8 or 176.8 CDDs, respectively. Due to these observations, a CDD threshold (CDD$\mathrm{T}_{\mathrm{LEAF}}$ ) of 175 CDDs was defined (i.e., initial symptoms can be expected as soon as the $\mathrm{CDDT}_{\mathrm{LEAF}}$ was greater than 175).

The model was validated with the data of the year 2008. Observed CDDs $\left(\mathrm{CDD}_{\mathrm{INC}}\right)$ until the occurrence of initial symptoms in 2008 were 172.2 to 193.5 (180.1 on average; Fig. 2).

The observed durations of the incubation period in 2008 were significantly correlated $(r=0.997 ; P<0.01)$ to the calculated duration of the incubation period (days between the day after inoculation and the day after passing the CDD threshold $\left[\mathrm{CDDT}_{\mathrm{LEAF}}\right]$ of 175). Initial symptoms occurred 1 day later than calculated five times, 2 days later one time, and 1 day earlier three times. In 17 of 26 cases, symptoms occurred on the calculated date. Pycnidia first appeared, on average over both years, 1.6 days after the observation of initial symptoms. The time between the appearance of first symptoms and the appearance of first pycnidia was 1 to 4 days (inoculation at 10 April 2007).

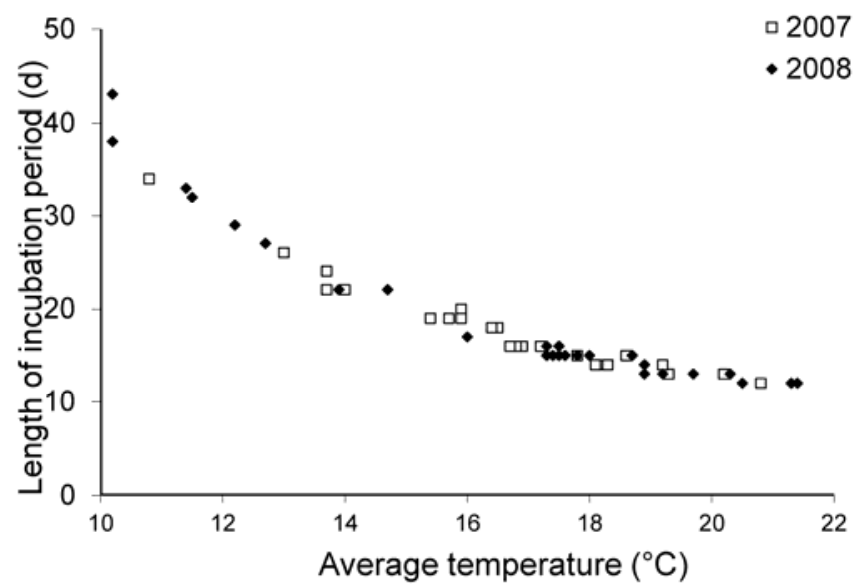

Fig. 1. Duration of the incubation period on leaves of potted vines ('MuellerThurgau') depending on the average temperature; years: 2007 and 2008.

Table 2. Coefficients of variation calculating cumulative degree-day (CDD) values using different lower and upper thresholds (average daily temperatures starting the day after inoculation until the day of the occurrence of first symptoms) on leaves of potted vines in 2007 ( $n=26$ inoculation dates)

\begin{tabular}{lcccc}
\hline $\begin{array}{l}\text { Lower } \\
\text { threshold }\left({ }^{\circ} \mathbf{C}\right)\end{array}$ & $\begin{array}{c}\text { Upper } \\
\text { threshold }\left({ }^{\circ} \mathbf{C}\right)\end{array}$ & $\begin{array}{c}\text { Average } \\
\text { CDD }\end{array}$ & $\begin{array}{c}\text { Standard } \\
\text { deviation }\end{array}$ & $\begin{array}{c}\text { Coefficient } \\
\text { of variation }\end{array}$ \\
\hline 0 & $-^{\mathrm{a}}$ & 283.5 & 30.1 & 10.6 \\
5 & 23 & 194.8 & 9.2 & 4.7 \\
5 & 24 & 195.3 & 9.0 & 4.6 \\
5 & 25 & 195.5 & 9.0 & 4.6 \\
6 & 23 & 177.2 & 7.6 & 4.3 \\
6 & 24 & 177.8 & 7.5 & $\mathbf{4 . 2}$ \\
6 & 25 & 178.0 & 7.7 & 4.3 \\
7 & 20 & 155.0 & 8.3 & 5.4 \\
7 & 21 & 157.4 & 7.9 & 5.0 \\
7 & 22 & 158.8 & 8.0 & 5.6 \\
7 & $26^{\mathrm{b}}$ & 180.7 & 9.9 & 5.5 \\
\hline
\end{tabular}

a Thresholds defined by Hoffman et al. (5).

b Thresholds defined by Northover (16).
Incubation period on clusters. In 2006, the duration of the incubation period on clusters remained constantly at 13 days for the first 3 weeks after flowering and increased up to 29 days for inoculations carried out 5 weeks after flowering. Later inoculations did not lead to any symptoms. In 2007, no symptoms appeared on leaves inoculated at $\mathrm{BBCH} 68$ (i.e., no incubation period was recordable). The duration of the incubation period on clusters inoculated the first 3 weeks after BBCH 68 was 13 days. Subsequently, the duration of the incubation period increased steadily up to 29 days for inoculations done 7 weeks after flowering. In 2008, incubation periods of 12 days were recorded for inoculations made one to 2 weeks after flowering. Thereafter, incubation periods up to 19 days for inoculations made during the 6 weeks after BBCH 68 were determined. No symptoms were observed on clusters inoculated 7 weeks after BBCH 68 (Table 3).

Influence of the phenological status of grape berries. To calculate the equation of the correction factor $c$ determining the CDD threshold on clusters, assessed value pair $\left(\mathrm{CDD}_{\text {INC }(6 ; 24)}\right.$ values until the appearance of symptoms on clusters; $\mathrm{CDD}_{>10}$ values at inoculation) were plotted against each other.

The recorded $\mathrm{CDD}_{\text {INC }(6 ; 24)}$ values (as the parameter describing the duration of incubation period) on grape were 168.9 to 223.0 CDDs, as long as the $\mathrm{CDD}_{>10}$ value (as the parameter describing the phenological status) was below 200 CDDs. After reaching BBCH 79 ("majority of berries touching"; 8), the duration of the incubation period was extended continuously (Fig. 3).

To calculate a correction factor describing the impact of the phenological development, the following equation proved to be best

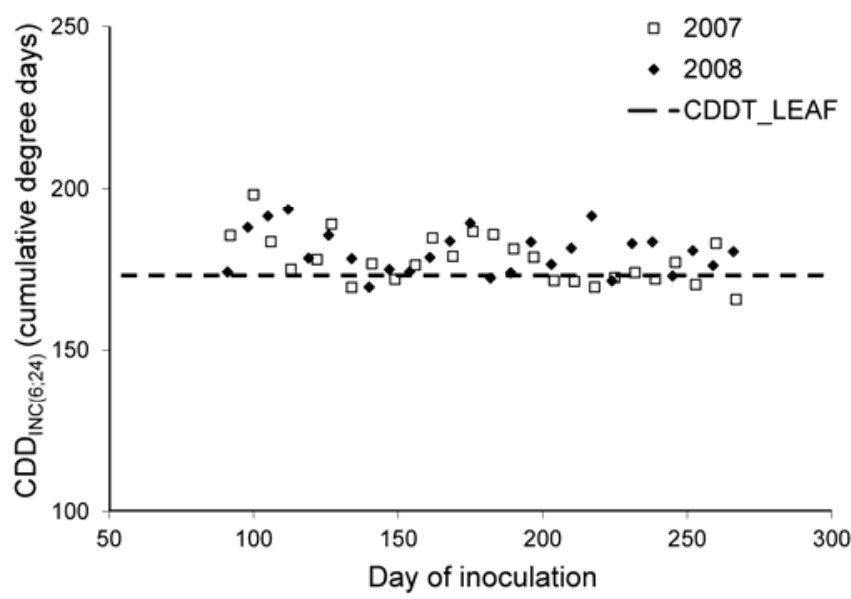

Fig. 2. Cumulative degree-days $\left(\operatorname{CDD}_{\mathbb{N N C}(6 ; 24)}\right)$ until the occurrence of first symptoms on leaves of potted vines ('Mueller-Thurgau'). The dashed line represents the defined cumulative degree-day threshold $\left(\mathrm{CDDT}_{\operatorname{LEAF}(6 ; 24)}\right)$ of $175 \mathrm{CDD}_{\text {INC }}$ (6;24); years: 2007 and 2008.

Table 3. Duration of the incubation period (expressed in days) on clusters in the field in relation to the time of inoculation in terms of weeks after BBCH 68 ("80\% of flowerhoods fallen") in the years 2006 to 2008

\begin{tabular}{cccc}
\hline & \multicolumn{3}{c}{ Duration of incubation period (days) ${ }^{\mathbf{a}}$} \\
\cline { 2 - 4 } Number of weeks $^{\mathbf{b}}$ & $\mathbf{2 0 0 6}$ & $\mathbf{2 0 0 7}$ & $\mathbf{2 0 0 8}$ \\
\hline-1 & n.s. & 18 & 18 \\
0 & 13 & n.s. & 15 \\
1 & 13 & 13 & 12 \\
2 & 13 & 13 & 12 \\
3 & 13 & 15 & 14 \\
4 & 15 & 20 & 17 \\
5 & 29 & 20 & 17 \\
6 & n.s. & 25 & 19 \\
7 & n.s. & 29 & n.s. \\
\hline
\end{tabular}

${ }^{\mathrm{a}}$ n.s. $=$ No symptoms were visible.

${ }^{b}$ Date of inoculation (weeks after BBCH 68). 
adapted: $c=-0.95 \times 10^{-10} \times x^{4}+0.80 \times 10^{-7} \times x^{3}-0.12 \times 10^{-4} \times x^{2}$ $-0.25 \times 10^{-4} \times x+1.07$, where $c$ is the correction factor for the phenological development of the clusters and $x$ is the $\mathrm{CDD}_{>10}$ value at inoculation. The coefficient of determination $\left(R^{2}\right)$ of this equation was 0.874 .

According to this equation, the calculated correction factor $c$ for defining the CDD threshold on clusters (CDDT CLUSTER(6;24) in respect of the corresponding phenological stage is shown in Figure 3.

At $\mathrm{CDD}_{<10}$ values between 0 and $210 \mathrm{CDDs}$, corresponding to "80\% of flowerhoods fallen" (BBCH 68) and "berries beginning to touch" (BBCH 77) (Table 1), the calculated correction factor $c$ stays at a relatively constant level of 1 to 1.1 . After this stage, the duration of the incubation period rises steadily up to a value of 2 at 440 CDDs $\left(\mathrm{CDD}_{>10}\right)$ (Fig. 3).

The validation of the model on clusters was made with the data given by Hoffman et al. (5) for inoculations 3 to 7 weeks after flowering in the year 2000 obtained in Riesling in Geneva, NY.
Table 4. Validation of the model for the duration of the incubation period (Duration) on clusters of 'Riesling' based on the observation data for inoculations conducted 3 to 7 weeks after flowering given by Hoffman et al. (5)

\begin{tabular}{lcccc}
\hline Weeks $^{\mathbf{a}}$ & Duration (days) & $\mathbf{C D H}_{\mathbf{I N C}(\mathbf{0} ;-)} \mathbf{b}$ & $\mathbf{C D D}_{\mathbf{I N C}(\mathbf{6} ;-)} \mathbf{c}^{\mathbf{c}}$ & $\mathbf{C D D T}_{(\mathbf{6} ; \mathbf{2 4})} \mathbf{d}^{\mathbf{d}}$ \\
\hline 3 & 15 & 7,430 & 219.6 & 191.9 \\
4 & 14 & 7,340 & 221.8 & 225.2 \\
5 & 13 & 7,290 & 225.8 & 271.8 \\
6 & 21 & 10,290 & 302.8 & 340.1 \\
7 & 22 & 10,750 & 315.9 & 371.3 \\
\hline
\end{tabular}

${ }^{a}$ Inoculation (weeks after flowering).

${ }^{\mathrm{b}} \mathrm{CDH}_{\mathrm{INC}(0 ;-)}=$ observed cumulative degree-hours (lower threshold: $0^{\circ} \mathrm{C}$; no upper threshold) given.

${ }^{c} \mathrm{CDD}_{\mathrm{INC}(6 ;-)}=$ calculated cumulative degree-days (lower threshold: $6^{\circ} \mathrm{C}$; no upper threshold).

${ }^{\mathrm{d}}$ CDDT $_{\text {CLUSTER (6;24) }}=$ calculated cumulative degree-day threshold (lower threshold: $6^{\circ} \mathrm{C}$; upper threshold: $24^{\circ} \mathrm{C}$ ) based on the inoculation dates given by Hoffman et al. (5) and the correction factor for grape phenology developed in the present examinations.

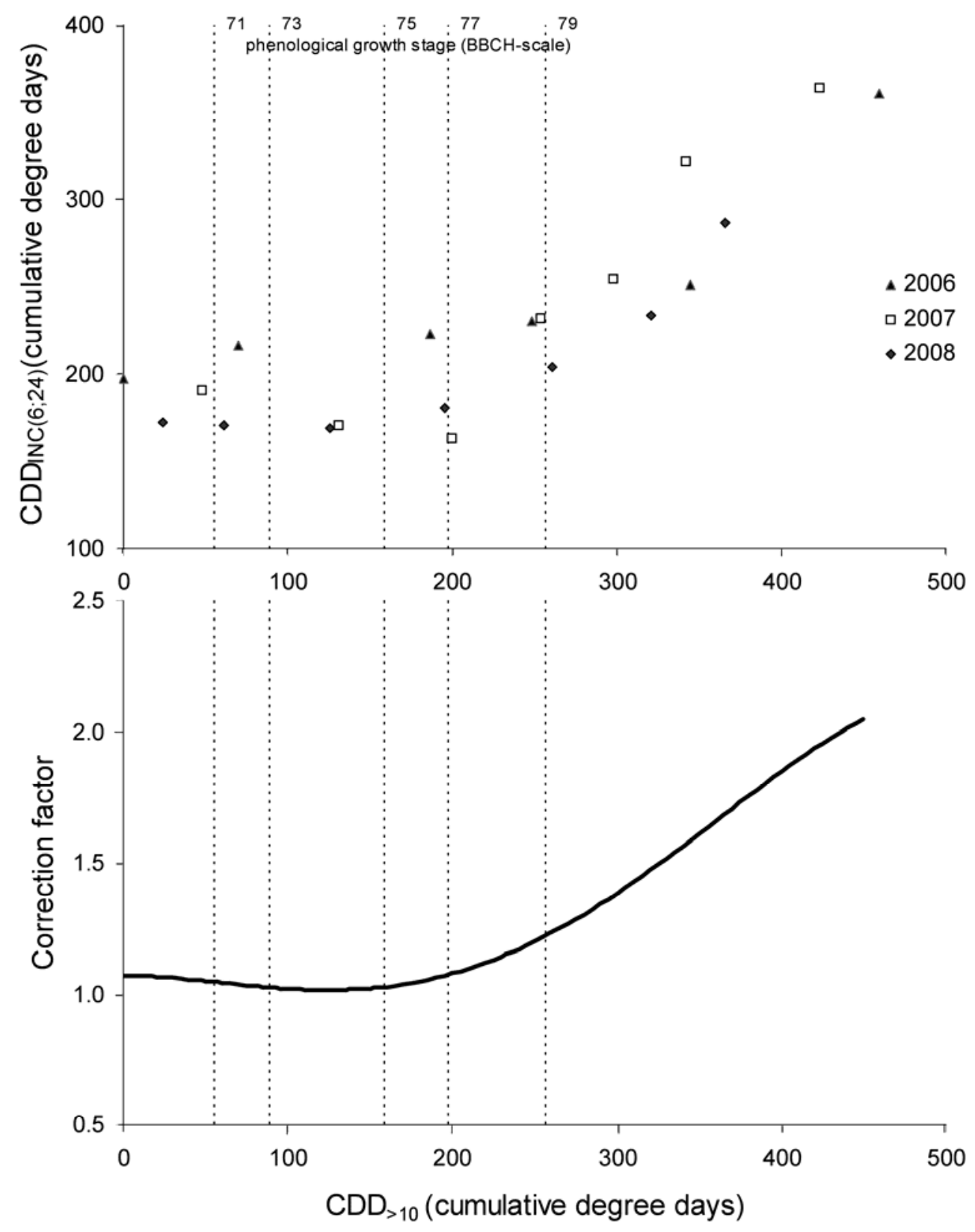

Fig. 3. A, Cumulative degree-days $\left(\mathrm{CDD}_{\mathbb{I N C}(6 ; 24)}\right)$ necessary for the appearance of first symptoms on clusters ('Riesling') plotted against the sum of average daily temperatures above $10^{\circ} \mathrm{C}$ from the day after reaching $\mathrm{BBCH} 68\left(\mathrm{CDD}_{>10}\right)$ at the day of inoculation; years: 2006 to 2008. $\mathrm{B}$, Correction factor to determine the CDD threshold $\left(\mathrm{CDDT}_{\text {CLUSTER(6;24) }}\right)$ on clusters depending on the stage of development $\left(\mathrm{CDD}_{>10}\right)$. 
The given data (Table 4 in Hoffman et al. [5]) for cumulative degree-hours above $0^{\circ} \mathrm{C}\left(\mathrm{CDH}_{\mathrm{INC}(0 ;-)}\right)$ were divided by 24 to calculate the $\mathrm{CDD}$ (lower threshold: $\left.0^{\circ} \mathrm{C}\right)\left(\mathrm{CDD}_{\mathrm{INC}\left(0_{;--}\right)}\right)$. To adjust this $\mathrm{CDD}$ to the present model, the $\mathrm{CDD}_{\mathrm{INC}(0 ;-)}$ was reduced by the duration of the incubation period (in days) multiplied by 6 (the lower threshold in the present model), assuming that no days with average daily temperatures below $6^{\circ} \mathrm{C}$ appeared. The result of this calculation is $\mathrm{CDD}_{\mathrm{INC}(6 ;-)}$. No correction for the upper threshold $\left(24^{\circ} \mathrm{C}\right.$ in the present model) was possible because no daily-based average temperatures were given by Hoffman et al. (5). The

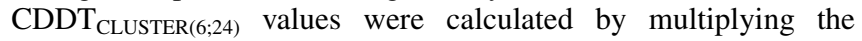
$\mathrm{CDDT}_{\mathrm{LEAF}(6 ; 24)}(175 \mathrm{CDDs})$ with the correction factor $c$ (phenological stage at inoculation in the trials of Hoffman et al. [5]). Basis for the correction factor is the $\mathrm{CDD}_{>10}$ value at moment of inoculation. This $\mathrm{CDD}_{>10}$ value was calculated by dividing the accumulated degree-hours after $50 \%$ bloom given by Hoffman et al. (5) in Table 2 by 24 (hours) and 10 times the number of days post bloom at which the inoculation took place. Contrary to the calculations in the present model, the start of summation for the $\mathrm{CDD}_{>10}$ value was, in case of the validation based on the data of Hoffman et al. (5), not BBCH 68 but $\mathrm{BBCH} 65$ (8) because data given were for this developmental stage (Table 4). Calculated $\mathrm{CDD}_{\mathrm{INC}(6 ;-)}$ values were plotted against the calculated CDDT $_{\text {CLUSTER(6;24) }}$ values. The correlation between $\mathrm{CDD}_{\mathrm{INC}(6 ;-)}$ and the $\mathrm{CDDT}_{\mathrm{CLUSTER}(6 ; 24)}$ values was significant $(r=0.94 ; P=0.017)$.

\section{Discussion}

Studies on leaves and clusters of $V$. vinifera showed that the incubation period of $G$. bidwellii is quite extended compared with other pathogens known in viticulture, such as $P$. viticola (15). Due to this fact, the potential number of infection cycles per growing season is limited for G. bidwellii. One possible reason for the relatively long-lasting incubation period may be found in the specific colonization pattern of $G$. bidwellii on plant tissues, which occurs in a two-step process (7). First, the mycelium of the fungus grows exclusively between the plant cuticle and the outer epidermis cell wall, without any visible symptoms (22). Characteristic primary infestation symptoms occur in the second, necrotic destruction phase (7). The switch between these two phases presumably takes place after the mycelia has colonized a sufficiently large area of the host tissue. Considering this, it may be assumed that the duration of the incubation period reflects the time required for intense host colonization. On leaves, pycnidia become visible close to the appearance of initial lesions (on average, 1.6 days thereafter). Even though the moment of pycnidia appearance on berries was not investigated systematically in the present study, first pycnidia were observed close to lesion development and became visible already before berries shriveled completely. Consequently, the incubation period (infection until appearance of initial lesions) and the latency period (infection until appearance of pycnidia) can be assumed to be approximately the same in practical plant protection strategies.

The duration of the incubation period on leaves turned out to be directly linked to temperature conditions. A model based on CDDs calculated from average daily temperatures between 6 and $24^{\circ} \mathrm{C}$ was demonstrated, in this study, to be best to describe mathematically the correlation between temperature conditions and incubation period duration. Using these thresholds, more consistent results were achieved than using the thresholds proposed by Northover (16) (lower threshold, $7^{\circ} \mathrm{C}$; upper threshold, $26^{\circ} \mathrm{C}$ ) or Hoffman et al. (5) (lower threshold, $0^{\circ} \mathrm{C}$; no upper threshold) (Table 2). Based on the present data on leaves, a CDD threshold $\left(\mathrm{CDDT}_{\mathrm{LEAF}}\right)$ of $175 \mathrm{CDDs}$ was determined and validated. After reaching this value, initial symptoms are expected to become visible). Present data were collected on $V$. vinifera Mueller-Thurgau. In 2006, pre-tests with artificial inoculation at six time points were conducted on potted vines of Riesling and Mueller-Thurgau in parallel. In each of the six series, initial symptoms on leaves appeared in both varieties on the same day. Those observations on leaves of different $V$. vinifera varieties indicated that the results gained on Mueller-Thurgau might be transferable to other $V$. vini- fera cultivars whereas, based on the data recorded by Spotts (21), the incubation period on V. labrusca or hybrid grape seems, by trend, to be shorter. Furthermore, the results of Spotts (21) indicate that the duration of the incubation period under constant temperature conditions is shorter than under fluctuation (as was the case in the present examinations). The same effect was also described for downy mildew of lettuce by Scherm and van Bruggen (17).

The present CDD-based model for grapevine enables both the temporal positioning of the pathogenesis (percentage of the total incubation period already passed at a certain time interval) and the calculation of the day on which first symptoms are expected to appear. For the latter, forecasted temperature data can be included in the calculation. This option especially emphasizes the excellence of a CDD-based model compared with a regression-based model.

Periods with constant average daily temperatures of over $20^{\circ} \mathrm{C}$ were not registered at the experimental site in 2007 or 2008 whereas, in hot regions, periods with such average temperatures may occur. Under those conditions, the present model has to be adapted. However, greenhouse observations suggest that, at temperatures above $20^{\circ} \mathrm{C}$, the incubation period on leaves would slightly decrease further but not fall below 9 days. However, these observations have to be verified. The examinations of Spotts (21) on non- $V$. vinifera varieties indicate that the duration of the incubation period will not decrease further above an average temperature of $23^{\circ} \mathrm{C}$.

Following the present model developed on leaves, incubation periods of more than 20 days would be very unlikely in wine-growing regions during the vegetation period. However, infected clusters were occasionally found under field conditions, even though no corresponding infection event was relatable in expected temporal proximity. The present observations as well as the studies of Hoffman et al. (5) show that the duration of the incubation period for clusters is in addition to the temperature, depending on the phenological state. This fact has to be respected by using a correction factor for the current phenological stage to calculate the CDD threshold on clusters.

Even though the present observations were obtained using a single isolate, the consistency with the results obtained by Hoffman et al. (5) using isolates from North America indicates that the developed model might be transferable to other regions. However, it has to be mentioned that the data presented by Hoffman et al. (5) consisted of only five data pairs. Adoptions could be necessary, especially in regions where temperature conditions are completely different than in the present study.

Infections on young berries are possible until 5 to 7 weeks post bloom, depending on the temperature conditions $(5,13)$. According to the observed incubation period durations, more than one infection cycle per season is possible on clusters. In fact, new symptoms on berries can often be directly linked to small shriveled berries in the same cluster, which were affected at an earlier stage. If weather conditions are favorable, infections around bloom could allow for two or even three infection cycles on clusters. The processes responsible for the increasing duration of the incubation period with ongoing phenological development on clusters are unknown thus far. Morphological changes during the ripening process probably induce barriers that suppress the spread of the subcuticle mycelium of G. bidwellii and the switch from the biotrophic to the necrotrophic colonization phase (7).

Thus far, the examinations of Spotts (20) and Cartolaro et al. (1) concerning the minimum wetness period requirements allow for a quite precise determination of occurred infection events. Combined with this knowledge, the present incubation period model could present a tool for a more targeted timing of fungicides with postinfection activity, such as triazoles or strobilurines $(2,4,18)$, because trials on leaves and clusters had shown that post-infection fungicide applications made when up to $50 \%$ (myclobutanil) or even $85 \%$ (pyraclostrobin) of the incubation period had passed were able to virtually suppress the occurrence of symptoms, regardless of the duration of the incubation period (12). However, if possible, curative applications should be placed as close as possible to observed infection events to guarantee optimal success. 
Furthermore, using this model, applications of fungicides with only protective activities can be timed precisely prior to the appearance of new symptoms (and subsequent fruiting bodies) and, with this, ensure an optimal protection of young plant tissues against following infections. Both the curative as well as the protective approach could improve disease management with a view to significantly minimize the number of black rot treatments per season without compromising the actual grape health status.

\section{Acknowledgments}

We thank B. Fuchs for the provision of historical phenological data; M. Pasquali and B. Hed for critical proofreading; E. Kecskeméti, N. Siebert, and W. Schoenbach for their excellent technical assistance; and M. Thiel, K. Fulton, and V. Peardon for English language support.

\section{Literature Cited}

1. Cartolaro, P., Pacreau, S., Clerjeau, M., and Maurin, G. 1993. Sensibilité des grappes au Black-rot. In: Proc. IOBC Working Group "Integrated Control in Viticulture". Bordeaux, France.

2. Ellis, M. A., Madden, L. V., and Wilson, L. L. 1986. Electronic grape black rot predictor for scheduling fungicides with curative activity. Plant Dis. 70:938-940.

3. Harms, M., Holz, B., Hoffmann, P. G., Lipps, H. P., and Silvanus, W. 2005. Occurrence of Guignardia bidwellii, the causal fungus of black rot on grapevine, in the vine growing areas of Rhineland-Palatinate, Germany. BCPC Symp. Proc. 81:127-132.

4. Hoffman, L. E., and Wilcox, W. F. 2003. Factors influencing the efficacy of myclobutanil and azoxystrobin for control of grape black rot. Plant Dis. 87:273-281.

5. Hoffman, L. E., Wilcox, W. F., Gadoury, D. A., and Seem, R. C. 2002. Influence of grape berry age on susceptibility to Guignardia bidwellii and its incubation period length. Phytopathology 92:1068-1076.

6. Jermini, M., and Gessler, C. 1996. Epidemiology and control of grape black rot in southern Switzerland. Plant Dis. 80:322-325.

7. Kuo, K. C., and Hoch, H. C. 1996. The parasitic relationship between Phyllosticta ampelicida and Vitis vinifera. Mycologia 88:626-634.

8. Lorenz, D. H., Eichhorn, K. W., Bleiholder, H., Klose, R., Meier, U., and Weber, E. 1995. Phenological growth stages of the grapevine, Vitis vinifera L. ssp. vinifera. Codes and descriptions according to the extended $\mathrm{BBCH}$ scale. Aust. J. Grape Wine Res. 1:100-103.

9. Luestner, G. 1935. Auftreten der Schwarzfäule (Black Rot) der Rebe in Deutschland. Nachrichtenb. Dtsch. Pflanzenschutzdienstes (Braunschweig) $15: 27$.

10. Molitor, D. 2009. Biologie und Bekämpfung der Schwarzfäule (Guignardia bidwellii) an Weinreben. Dissertation, Geisenheimer Berichte Bd. 65. Gesellschaft zur Förderung der Forschungsanstalt Geisenheim, Geisenheim, Germany

11. Molitor, D. 2009. Wann blüht der Riesling? Dtsch. Weinmagazin 20-22

12. Molitor, D., Baus, O., and Berkelmann-Loehnertz, B. 2011. Protective and curative grape black rot control potential of pyraclostrobin and myclobutanil. J. Plant Dis. Prot. 118:161-187.

13. Molitor, D., and Berkelmann-Loehnertz, B. 2011. Simulating the susceptibility of clusters to grape black rot infections depending on their phenological development. Crop Prot. 30:1649-1654.

14. Mueller, K. 1934. Jahresbericht des Badischen Weinbauinstitutes in Freiburg i. B. für das Jahr 1933:54.

15. Mueller, K., and Sleumer, H. 1934. Biologische Untersuchungen über die Peronosporakrankheit des Weinstockes mit besonderer Berücksichtigung ihrer Bekämpfung nach der Inkubationskalendermethode. Special print out of "Landwirtschaftliche Jahrbücher" 79.

16. Northover, P. R. 1998. The relationship of the number of wetting periods and accumulated degree-days to sporulation of Guignardia bidwellii (Ellis) Viala \& Ravaz in vineyards. Master's thesis, Pennsylvania State University.

17. Scherm, H., and van Bruggen, A. H. C. 1994. Effects of fluctuating temperatures on the latent period of lettuce downy mildew (Bremia lactucae). Phytopathology 84:853-859.

18. Schultz, H. R. 1992. An empirical-model for the simulation of leaf appearance and leaf-area development of primary shoots of several grapevine ( $\mathrm{Vi}$ tis vinifera L) canopy-systems. Sci. Hortic. 52:179-200.

19. Spotts, R. A. 1977. Chemical eradication of grape black rot caused by Guignardia bidwellii. Plant Dis. Rep. 61:125-128.

20. Spotts, R. A. 1977. Effect of leaf wetness duration and temperature on infectivity of Guignardia bidwellii on grape leaves. Phytopathology 67:1378-1381.

21. Spotts, R. A. 1980. Infection of grape by Guignardia bidwellii-factors affecting lesion development, conidial dispersal, and conidial populations on leaves. Phytopathology 70:252-255.

22. Ullrich, C. I., Kleespies, R. G., Enders, M., and Koch, E. 2008. Biology of the black rot pathogen, Guignardia bidwellii, its development in susceptible leaves of grapevine Vitis vinifera. J. Cultiv. Plants 61:82-90. 